Supporting Information for:

\title{
Tunable Fractal Nanostructures for Surface-Enhanced Raman Scattering via Templated Electrodeposition of Silver on Low-Energy Surfaces
}

Joshua Raveendran ${ }^{1}$, Kevin G. Stamplecoskie ${ }^{2}$ and Aristides Docoslis ${ }^{{ }^{*}}$

1 QuSENS Laboratory, Department of Chemical Engineering, Queen's University, Kingston, ON, K7L 3N6, Canada;

2 Department of Chemistry, Queen's University, Kingston, ON, K7L 3N6, Canada;

* Correspondence: docoslis@queensu.ca; Tel.: +1-613-533-6949

DC Bias Assemblies .....................................................................................................2

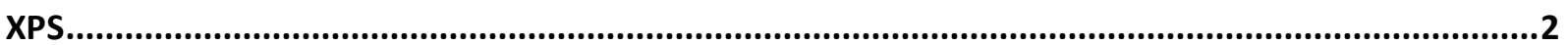

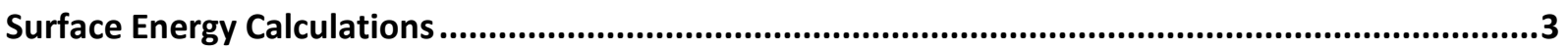

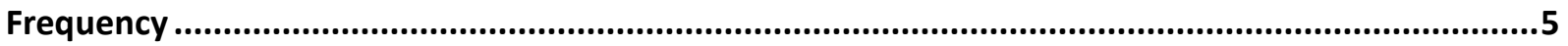

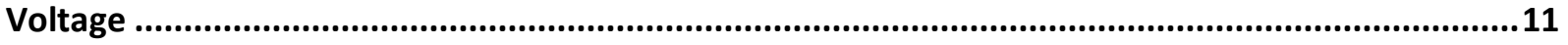

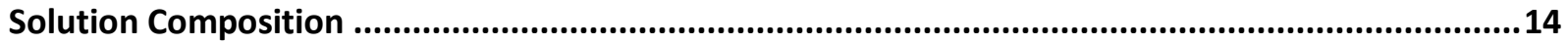

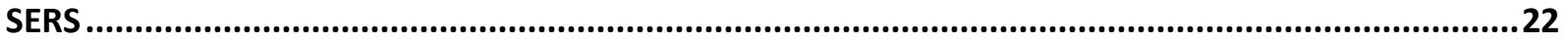

References .............................................................................................................23 

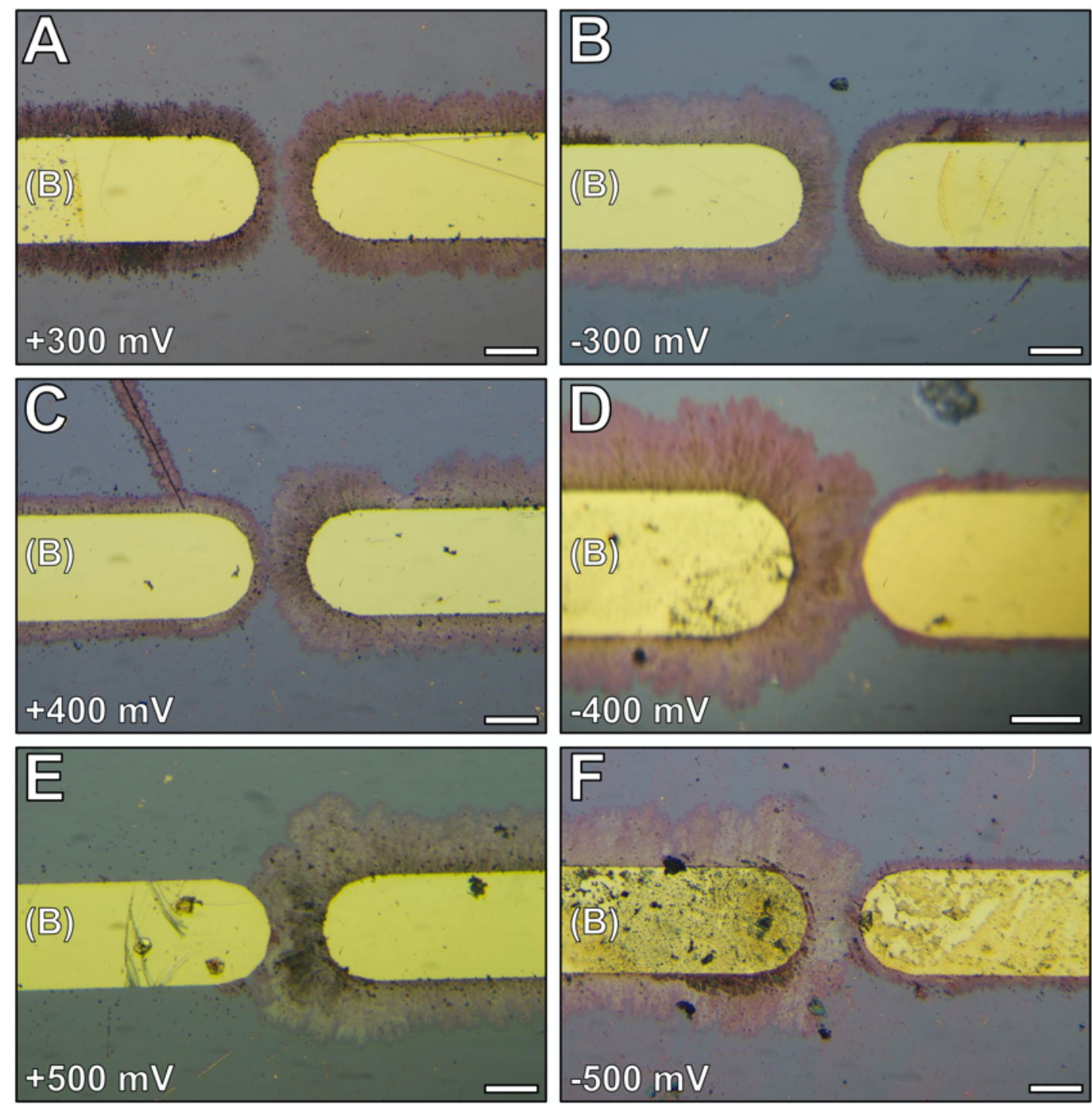

Figure S1: Deposition formed at various DC biases with an AC sinusoid electrical signal of 2.5

$\mathrm{Vpp}$ at $10 \mathrm{~Hz}$. All structures were formed using a $2 \mathrm{mM} \mathrm{Na}_{3} \mathrm{C}_{6} \mathrm{H}_{5} \mathrm{O}_{7}$ and $0.5 \mathrm{mM} \mathrm{AgNO}_{3}$

solution. Scale bar is 100 microns. (B) indicates which electrode was subjected to the bias.

XPS

X-ray photoelectron spectroscopy (XPS) was performed on the nanostructures to identify their composition. As shown in Figure S2, the structures have single peaks for Ag 3d 5/2 and 3/2 at binding energies that match the expected values for metallic Ag with FWHM values of 0.90 and 0.82 respectively. If Ag oxide was present, we would expect either for the single peak to be located at a lower binding energy or secondary peak present. The $\mathrm{O} 1 \mathrm{~s}$ section similarly shows little to no signal from binding energies associated with $\mathrm{AgO}_{\text {or }} \mathrm{Ag}_{2} \mathrm{O}(<530 \mathrm{eV})$ further strengthening our hypothesis the nanostructures are composed largely if not entirely of metallic Ag. The XPS measurements were performed approximately 4 days after the nanostructures were formed and simply stored in an unsealed covered petri dish. 

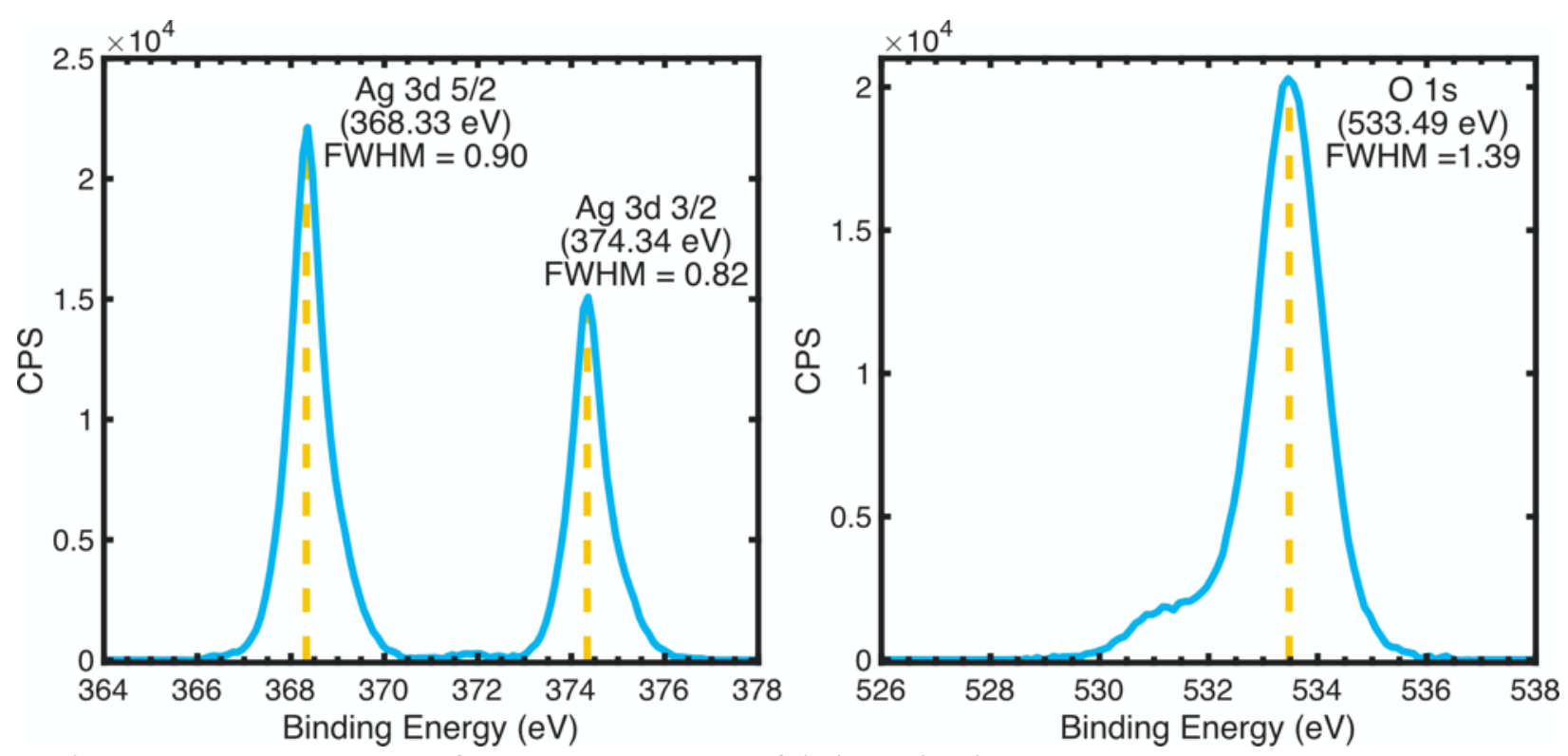

Figure S2: XPS spectra of Ag nanostructures fabricated using a solution of $2 \mathrm{mM} \mathrm{Na}_{3} \mathrm{C}_{6} \mathrm{H}_{5} \mathrm{O}_{7}$ and $0.5 \mathrm{mM} \mathrm{AgNO} 3$ and electrical signal of $10 \mathrm{~Hz}$ and $3 \mathrm{Vpp}$ was applied for 10 minutes.

\section{Surface Energy Calculations}

The van Oss-Chaudhury-Good (OCG) equation (S1), was used to estimate the surface energy properties of substrates. The equation relates the surface energy of solids to the surface tension of liquids and contact angle measurements: ${ }^{1}$

$$
\gamma_{L}(1+\cos \theta)=-2\left[\sqrt{\gamma_{L}^{L W} \gamma_{S}^{L W}}+\sqrt{\gamma_{L}^{+} \gamma_{S}^{-}}+\sqrt{\gamma_{L}^{-} \gamma_{S}^{+}}\right]
$$

Where $\theta$ is the contact angle, $\gamma$ is the surface energy/tension, subscripts L represent the liquid phase and S represent the substrate, superscripts LW, + and - represent components of the total surface tension, namely, apolar, electron-acceptor and electron-donor, respectively with air being the surrounding medium. The electron acceptor and donor components can be combined together to account for the total polar (acid-base) component for surface tension $\left(\gamma_{i}^{A B}=2 \sqrt{\gamma_{i}^{+} \gamma_{i}^{-}}\right)$. The polar and apolar components can be summed together to estimate the total surface energy/tension for a solid or liquid respectively $\left(\Delta \gamma=\Delta \gamma^{L W}+\Delta \gamma^{A B}\right)$. Contact angle measurements were taken on all substrates using water, hexadecane and ethylene glycol. All substrates were cleaned prior to measurements using a wash of acetone, ethanol and DI water before being dried. Equation S1 was used to solved a system of equations for the substrate's surface energy values in Matlab using the contact angles and values summarized in table S1.

Table S1: Surface tension properties of solvents used for contact angle measurements to calculate surface properties of various substrates $\left(\frac{m J}{m^{2}}\right) .^{2}$

\begin{tabular}{cccc}
\hline Solvent & $\gamma^{\mathrm{LW}}$ & $\gamma^{\mathrm{AB}+}$ & $\gamma^{\mathrm{AB}-}$ \\
\hline Water & 21.8 & 25.5 & 25.5 \\
Hexadecane & 27.6 & 0 & 0
\end{tabular}


The nanostructure samples, due to being a composite substrate, required additional calculations. The Cassie-Baxter equation, equation S2 was used to estimate contact angle on pure $\mathrm{Ag}$ nanostructures surface properties with an assumed surface coverage based on SEM and optical microscopy images. The surface coverage of nanostructures was estimated as the following:

- $f_{\text {dendrites }}=0.1875$

- $f_{\text {gold }}=0.25$

- $f_{\text {silane wafer }}=0.5625$

$$
\begin{gathered}
\cos \theta=\Sigma f_{i} \cos \theta_{i} \quad(\mathrm{~S} 2) \\
\cos \theta_{\text {measured }}=f_{\text {dendrites }} \cos \theta_{\text {dendrites }}+f_{\text {gold }} \cos \theta_{\text {gold }}+f_{\text {silane wafer }} \cos \theta_{\text {silane wafer }}
\end{gathered}
$$

Once the surface properties were calculated, the interactions between the nanostructures and various substrates in water were calculated. The interaction energy looked specifically at the change in Gibb's free energy as the two approached one another at the point of contact $\left(l_{0}=0.157\right.$ $\mathrm{nm})$ i.e., as a nanostructure was approaching a gold island in water, does the change in Gibb's free energy at the point of contact predict the two structures making contact or being repelled from one another based on thermodynamics? The total change in energy was calculated from the sum of van der Waals and acid-base interactions when the nanostructures approach other substrates with the geometry of both substrates assumed to be parallel plates (equations S4-S6).

Van der Waals Interaction

$$
\Delta G_{132 \|}^{L W}\left(l_{0}\right)=-2\left(\sqrt{\gamma_{1}^{L W}}-\sqrt{\gamma_{3}^{L W}}\right)\left(\sqrt{\gamma_{2}^{L W}}-\sqrt{\gamma_{3}^{L W}}\right)
$$

Acid Base interactions

$$
\begin{gathered}
\Delta G_{132\|\|}^{A B}\left(l_{0}\right)=-2\left[\left(\sqrt{\gamma_{1}^{+}}-\sqrt{\gamma_{3}^{+}}\right)\left(\sqrt{\gamma_{1}^{-}}-\sqrt{\gamma_{3}^{-}}\right)+\left(\sqrt{\gamma_{2}^{+}}-\sqrt{\gamma_{3}^{+}}\right)\left(\sqrt{\gamma_{2}^{-}}-\sqrt{\gamma_{3}^{-}}\right)-\right. \\
\left.\left(\sqrt{\gamma_{1}^{+}}-\sqrt{\gamma_{2}^{+}}\right)\left(\sqrt{\gamma_{1}^{-}}-\sqrt{\gamma_{2}^{-}}\right)\right]
\end{gathered}
$$

Total

$$
\Delta G_{132 \|}^{T}\left(l_{0}\right)=\Delta G_{132 \|}^{L W}\left(l_{0}\right)+\Delta G_{132 \|}^{A B}\left(l_{0}\right)
$$

Table S2 summarizes all surface energy/tension values and change in Gibb's free energy calculated. A glass slide functionalized with the same silane was estimated to have a surface energy of $11.1 \frac{\mathrm{mJ}}{\mathrm{m}^{2}}$, which is close to our calculated value of $12.5 \frac{\mathrm{mJ}}{\mathrm{m}^{2}}{ }^{3}$ As well, the estimate total change in Gibb's free energy matched the experimental results with gold and silanized surfaces having attractive interactions while $\mathrm{Ag}$ nanostructures and plasma cleaned wafers having repulsive interactions with $\mathrm{Ag}$ nanostructures.

Table S2. Surface tension values $\left(\mathrm{mJ} / \mathrm{m}^{2}\right)$ for various substrates tested and change in Gibb's free energy $\left(\mathrm{mJ} / \mathrm{m}^{2}\right)$ for various substrates and nanostructures in water. Negative $\Delta \mathrm{G}$ value indicates two surfaces have an attractive interaction while a positive value indicates repulsion between the substrate and nanostructures in water at the point of contact. 


\begin{tabular}{c|ccc|ccc}
\hline & \multicolumn{3}{c}{$\begin{array}{c}\text { Surface Energy/Tension } \\
\left(\frac{\mathrm{mJ}}{\mathrm{m}^{2}}\right)\end{array}$} & \multicolumn{3}{c}{$\begin{array}{c}\text { Calculated Interaction Energy at } \\
\text { Contact }\left(\frac{\mathrm{mJ}}{\mathrm{m}^{2}}\right)\end{array}$} \\
\hline Ag nanostructures vis $a$ & $\gamma \mathrm{s}^{\mathrm{LW}}$ & $\boldsymbol{\gamma} \mathrm{s}^{+}$ & $\boldsymbol{\gamma} \mathrm{s}^{-}$ & $\Delta \mathrm{G}^{\mathrm{LW}}$ & $\Delta \mathrm{G}^{\mathrm{AB}}$ & $\Delta \mathrm{G}^{\mathrm{T}}$ \\
vis: & & & & & & -18.97 \\
\hline Gold electrode/island & 25.92 & 0.34 & 3.95 & 0.02 & -18.95 \\
Plasma cleaned wafer & 26.45 & 0.86 & 74.60 & 0.02 & 38.24 & 38.26 \\
Silanized wafer & 10.59 & 0.49 & 1.94 & -0.07 & -24.34 & -24.41 \\
Ag nanostructures & 21.58 & 0.49 & 34.88 & -0.001 & 14.89 & 14.89 \\
\hline
\end{tabular}

\section{Frequency}

Nanostructures were fabricated using a solution of $2 \mathrm{mM} \mathrm{Na}_{3} \mathrm{C}_{6} \mathrm{H}_{5} \mathrm{O}_{7}$ and $0.5 \mathrm{mM} \mathrm{AgNO}$ with a voltage of $2.5 \mathrm{Vpp}$ except for the deposition made under DC conditions which used a voltage of $1.5 \mathrm{~V}$. 

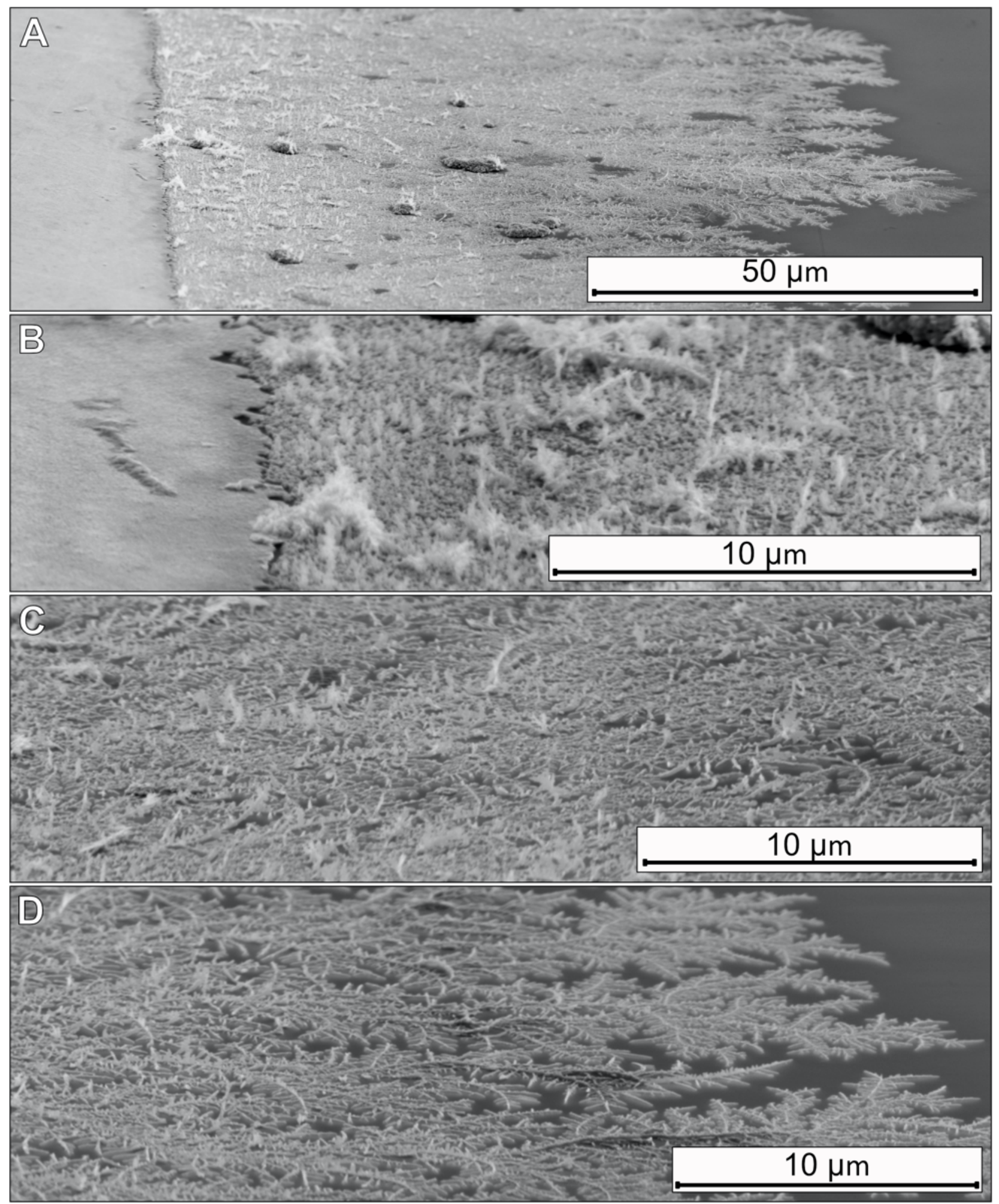

Figure S3: Tilted SEM image of nanostructures deposited using an electrical signal $10 \mathrm{~Hz}$ and $2.5 \mathrm{Vpp}$ for 10 minutes with a solution composed of $2 \mathrm{mM} \mathrm{Na}_{3} \mathrm{C}_{6} \mathrm{H}_{5} \mathrm{O}_{7}$ and $0.5 \mathrm{mM} \mathrm{AgNO}_{3}$. In all images, the electrode is on the left side. (A) is a wide view of the nanostructures deposited. (B) is zoom in of nanostructures formed near the electrode edge. (C) is of nanostructures formed in the middle section. (D) is focused on the tips of the nanostructures formed. 
Figures S4-7 are SEM images of nanostructures made using an increasing frequency.
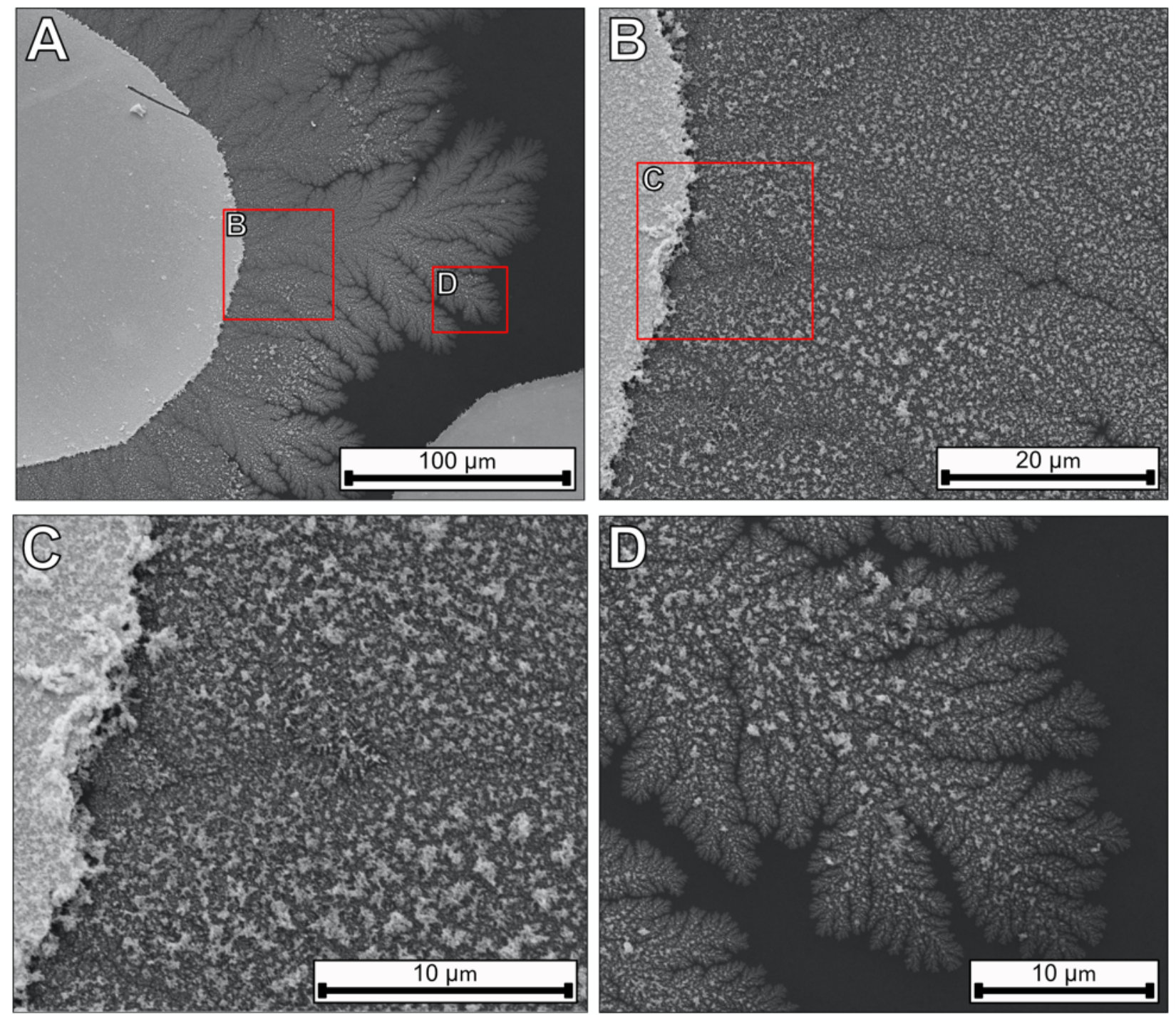

Figure S4: Deposition performed using using an AA battery (1.5 V) for 10 minutes with a solution composed of $2 \mathrm{mM} \mathrm{Na}_{3} \mathrm{C}_{6} \mathrm{H}_{5} \mathrm{O}_{7}$ and $0.5 \mathrm{mM} \mathrm{AgNO}_{3}$. (A) Nanostructures formed at both electrode tips. (B) Nanostructures formed on single electrode tip. (C) Nanostructures formed near the electrode edge in the electrode gap. (D) Higher resolution image of nanostructures formed away from the electrode edge in the electrode gap. 

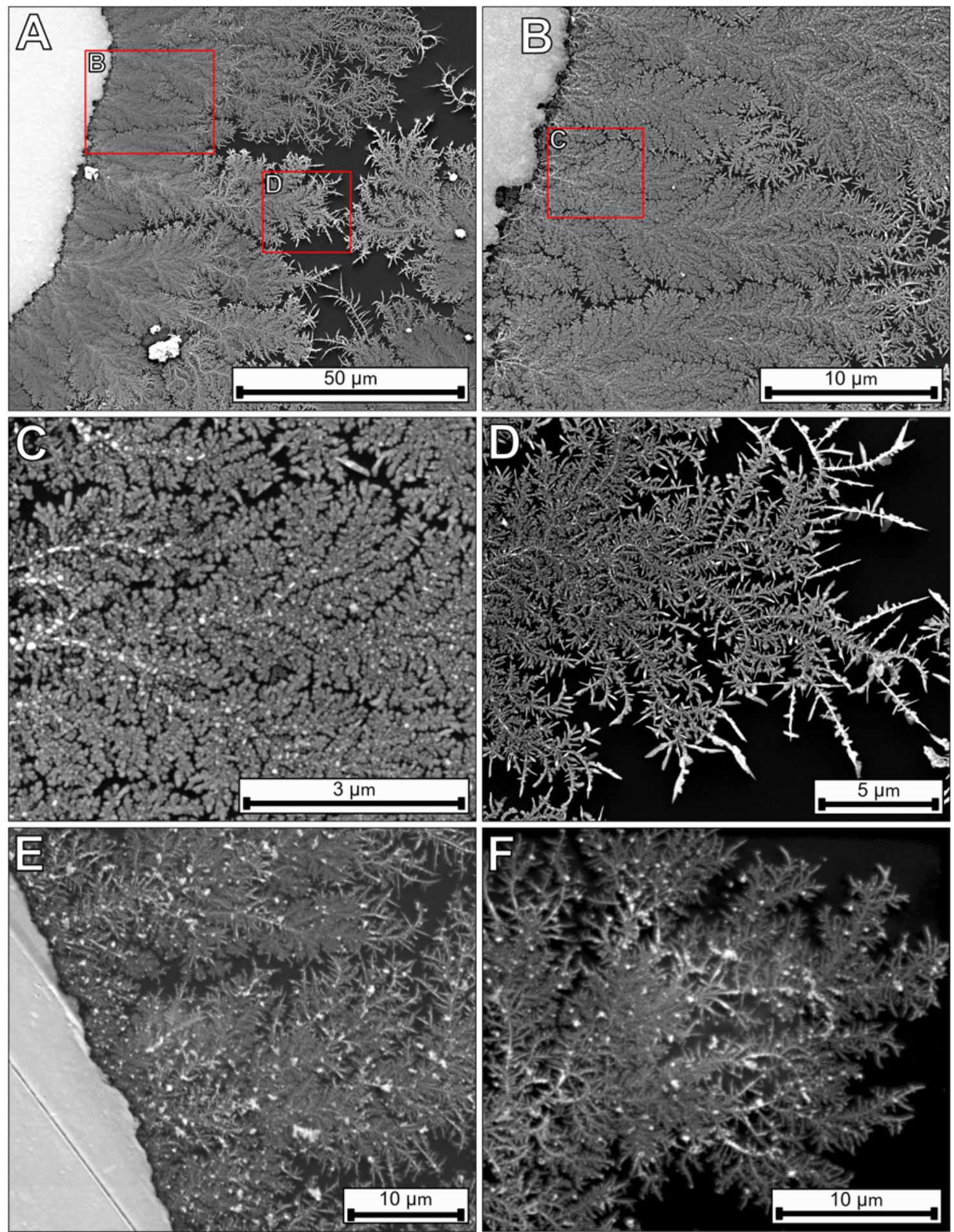

Figure S5: Deposition performed using an electrical signal $0.01 \mathrm{~Hz}$ and $2.5 \mathrm{Vpp}$ for 10 minutes with a solution composed of $2 \mathrm{mM} \mathrm{Na}_{3} \mathrm{C}_{6} \mathrm{H}_{5} \mathrm{O}_{7}$ and $0.5 \mathrm{mM} \mathrm{AgNO}_{3}$. (A) Nanostructures formed at both electrode tips. (B) Nanostructures formed on single electrode tip. (C) Nanostructures formed near the electrode edge in the electrode gap. (D) Higher resolution image of nanostructures formed away from the electrode edge in the electrode gap. (E) Nanostructures formed near the electrode edge away from the electrode gap. (F) Higher resolution image of nanostructures formed far from the electrode edge on the lateral side of the electrodes. 

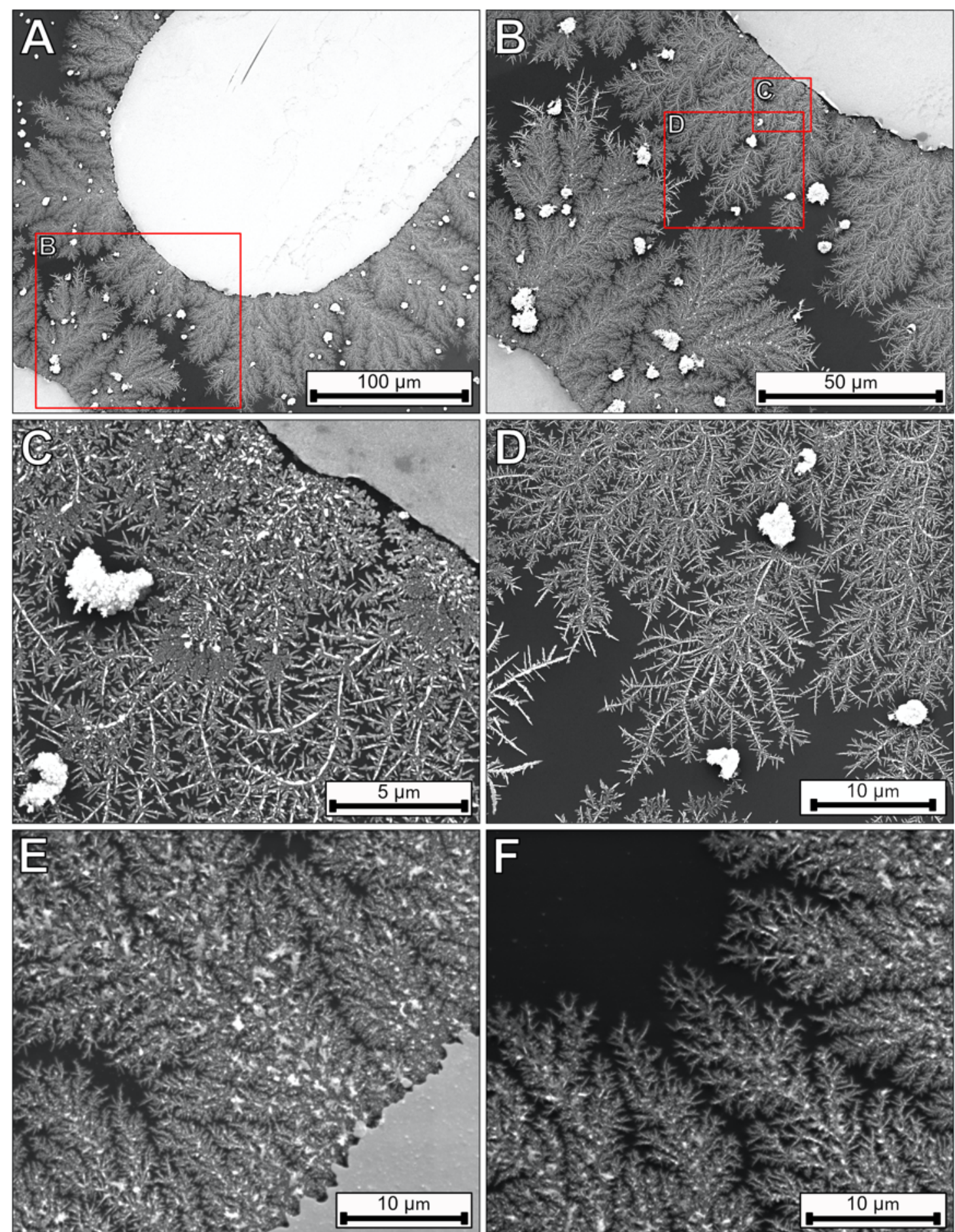

Figure S6: Deposition performed using an electrical signal of $0.1 \mathrm{~Hz}$ and $2.5 \mathrm{Vpp}$ for 10 minutes with a solution composed of $2 \mathrm{mM} \mathrm{Na}_{3} \mathrm{C}_{6} \mathrm{H}_{5} \mathrm{O}_{7}$ and $0.5 \mathrm{mM} \mathrm{AgNO}$. (A) Nanostructures formed at both electrode tips. (B) Nanostructures formed on single electrode tip. (C) Nanostructures

formed near the electrode edge in the electrode gap. (D) Higher resolution image of nanostructures formed away from the electrode edge in the electrode gap. (E) Nanostructures formed near the electrode edge away from the electrode gap. (F) Higher resolution image of nanostructures formed far from the electrode edge on the lateral side of the electrodes. 

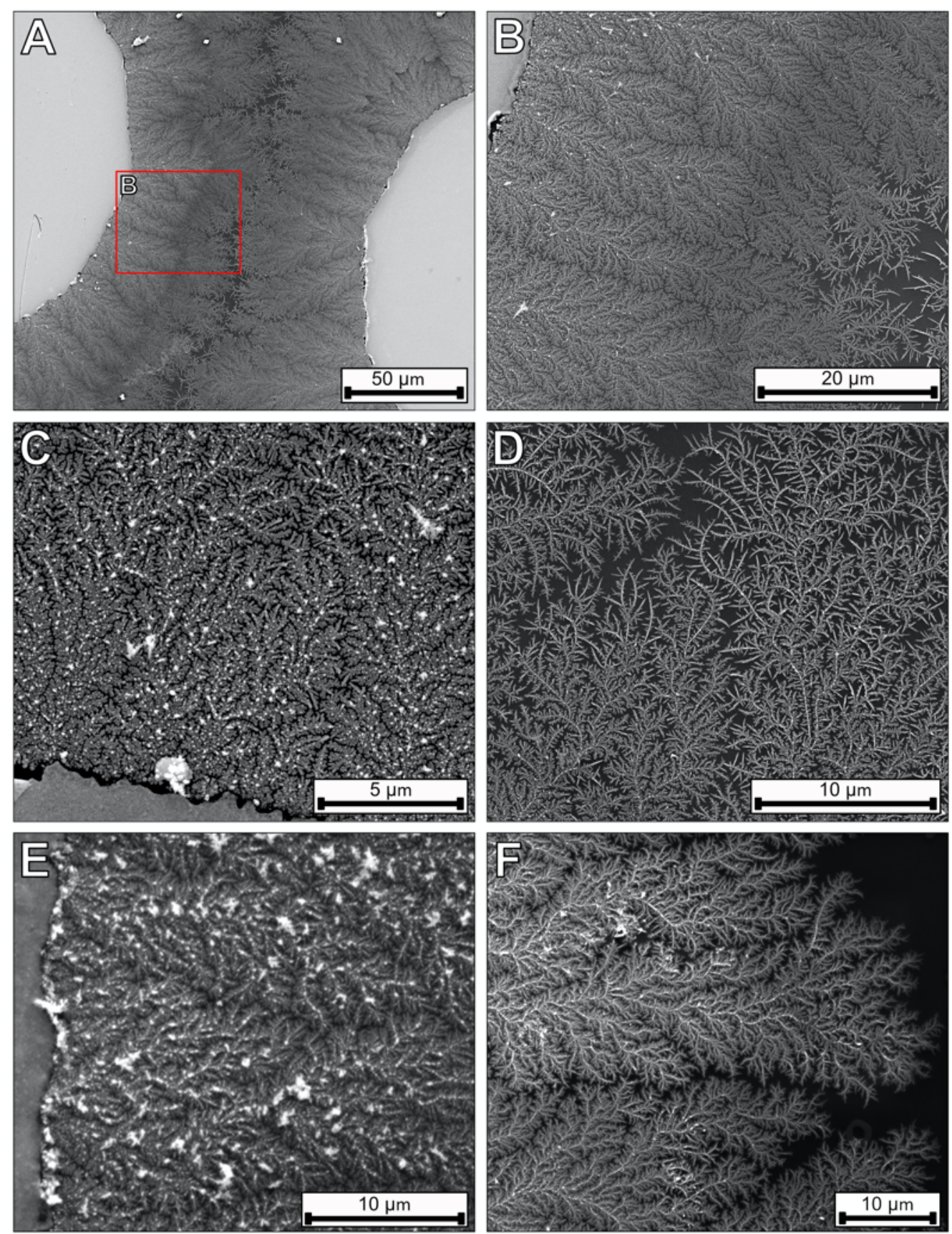

Figure S7: Deposition performed using an electrical signal of $1.0 \mathrm{~Hz}$ and $2.5 \mathrm{Vpp}$ for 10 minutes with a solution composed of $2 \mathrm{mM} \mathrm{Na}_{3} \mathrm{C}_{6} \mathrm{H}_{5} \mathrm{O}_{7}$ and $0.5 \mathrm{mM} \mathrm{AgNO}$. (A) Nanostructures formed at both electrode tips. (B) Nanostructures formed on single electrode tip. (C) Nanostructures formed near the electrode edge in the vicinity of the electrode gap. (D) Higher resolution image of nanostructures formed away from the electrode edge in the vicinity of the electrode gap. (E)

Nanostructures formed near the electrode edge away from the electrode gap. (F) Higher resolution image of nanostructures formed far from the electrode edge on the lateral side of the electrodes. 
Nanostructures deposited using different frequencies were all evaluated as potential SERS substrates. Figure S8 displays the SERS signal of R6G on the various nanostructures.
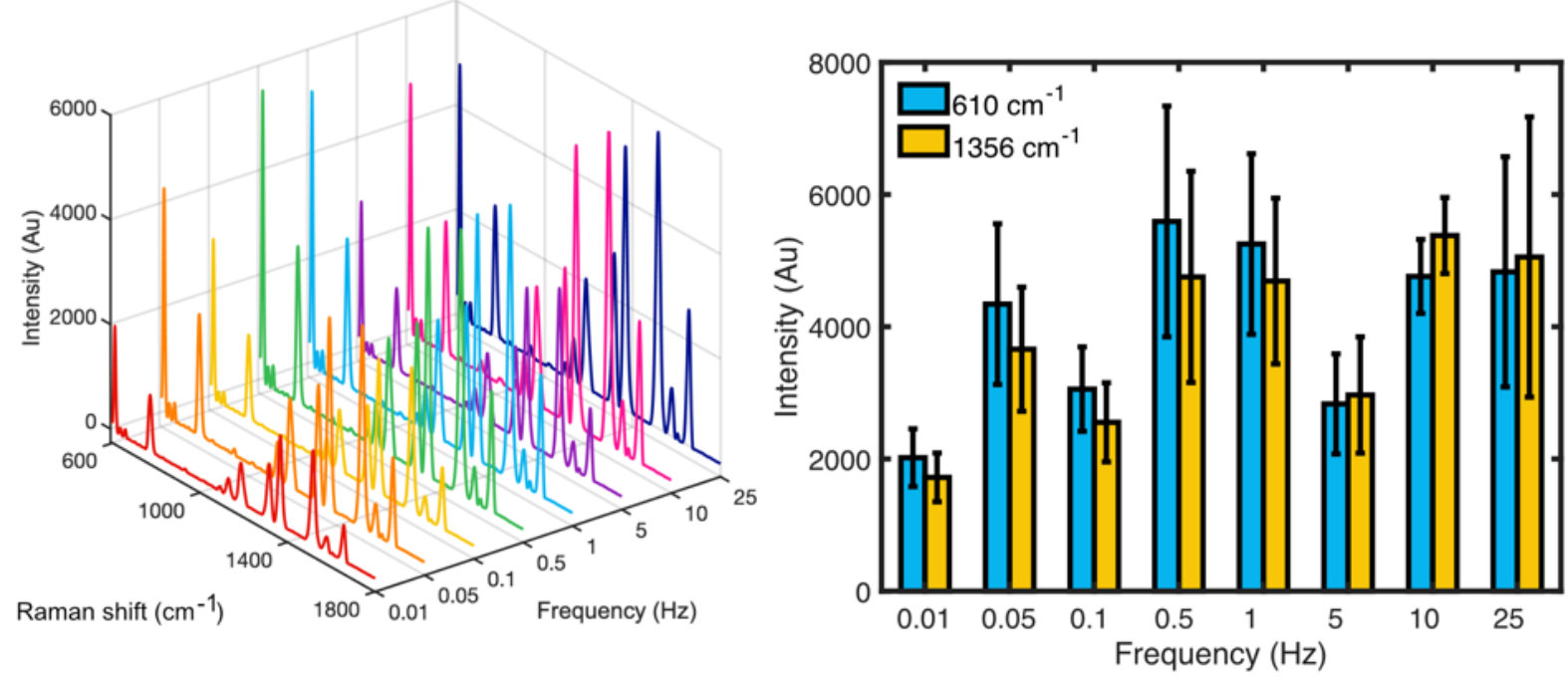

Figure S8:SERS signal of R6G (10-5 M) from nanostructures fabricated using different frequencies. Electrical signal of $2.5 \mathrm{Vpp}$ was applied for 10 minutes with a solution of $2 \mathrm{mM}$ $\mathrm{Na}_{3} \mathrm{C}_{6} \mathrm{H}_{5} \mathrm{O}_{7}$ and $0.5 \mathrm{mM} \mathrm{AgNO}_{3}$.

\section{Voltage}

Nanostructures deposited using different voltages and frequency of $10 \mathrm{~Hz}$ were all evaluated as potential SERS substrates. Figure S9 displays the SERS signal of R6G on the various nanostructures.
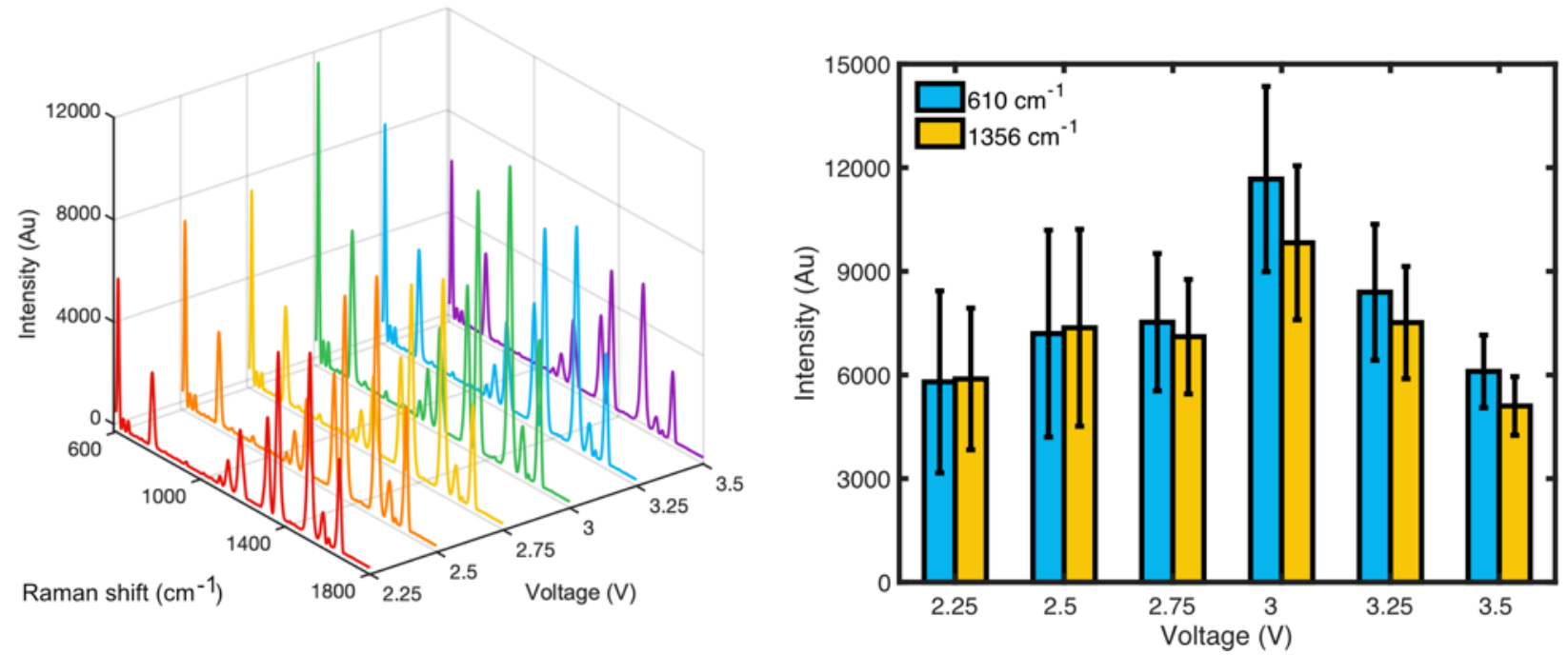

Figure S9: SERS signal of R6G $\left(10^{-5} \mathrm{M}\right)$ from nanostructures fabricated using different voltages. All noanostructures fabricated with a solution of $2 \mathrm{mM} \mathrm{Na}_{3} \mathrm{C}_{6} \mathrm{H}_{5} \mathrm{O}_{7}$ and $0.5 \mathrm{mM} \mathrm{AgNO}_{3}$ and a frequency of $10 \mathrm{~Hz}$ for 10 minutes. 
Assemblies were performed using various voltages at $10 \mathrm{~Hz}$ with both sine and square electrical signal (Figure S10). Using images taken every minute, the growth rates of the structures was estimated, see Figure S11 and Table S3.

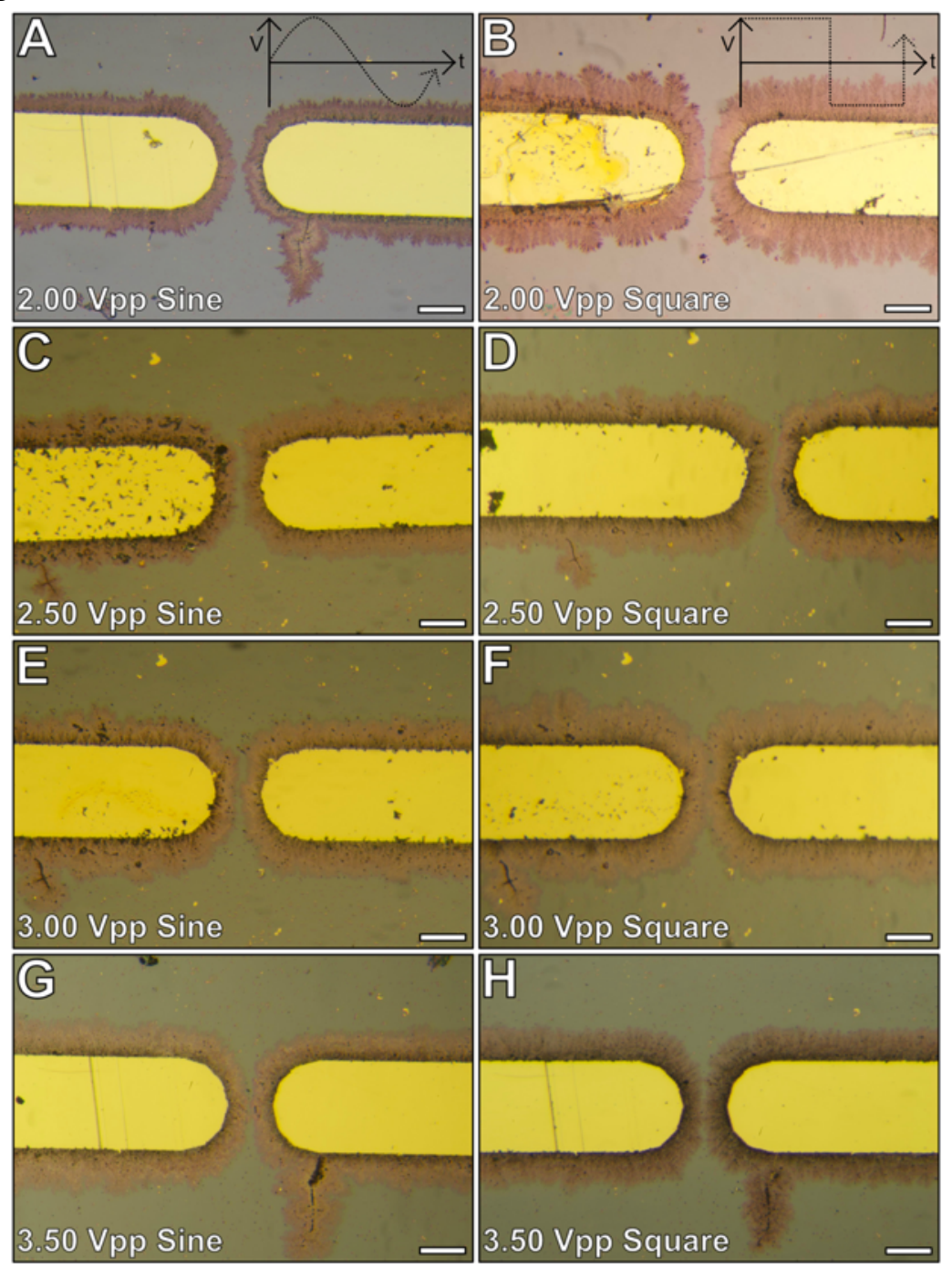

Figure S10: Deposition formed at various voltages using either a sine or square wave signal. All structures were formed using a $2 \mathrm{mM} \mathrm{Na}_{3} \mathrm{C}_{6} \mathrm{H}_{5} \mathrm{O}_{7}$ and $0.5 \mathrm{mM} \mathrm{AgNO}_{3}$ solution and a frequency of $10 \mathrm{~Hz}$ for 10 minutes. Scale bar is 100 microns. 

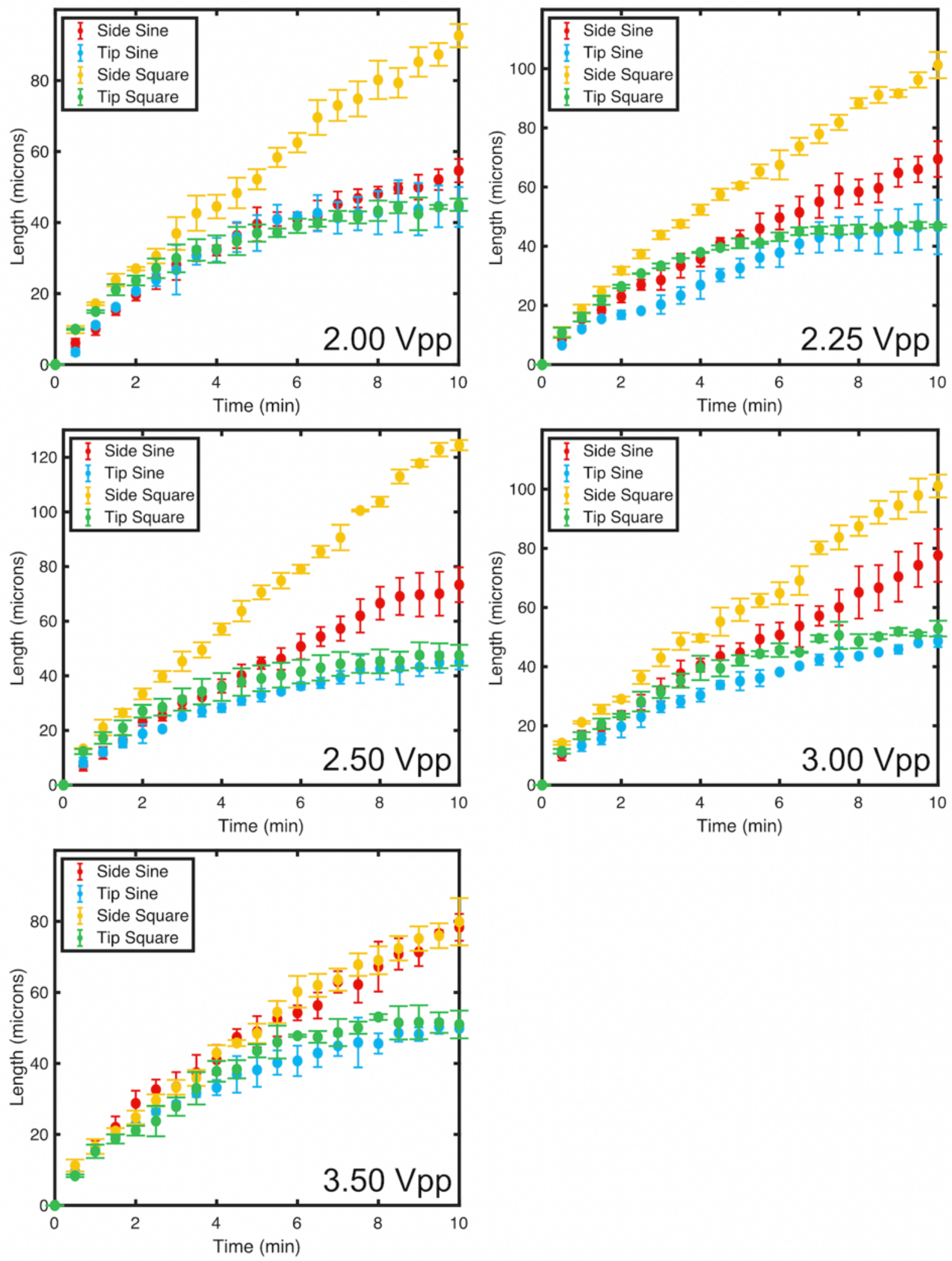

Figure S11: Growth measurements of dendrites formed using a $2 \mathrm{mM} \mathrm{Na}_{3} \mathrm{C}_{6} \mathrm{H}_{5} \mathrm{O}_{7}$ and $0.5 \mathrm{mM}$ $\mathrm{AgNO}_{3}$ solution and a frequency of $10 \mathrm{~Hz}$. Measurements at the tips and sides were average from 2 and 4 measurements respectively. 
Table S3: Summary of growth rate calculations where both the voltage and shape of electrical signal was changed. Linear fitting of growth curves evaluated using $\mathrm{R}^{2}$ values. Growth rate for nanostructures grown on side of microelectrodes, perpendicular to the tips of the microelectrodes.

\begin{tabular}{cccc}
\hline Voltage $(\mathrm{Vpp})$ & Voltage $\left(\mathrm{V}_{\mathrm{RMS}}\right)$ & Growth rate $(\mu \mathrm{m} /$ minute $)$ & $\mathrm{R}^{2}$ \\
\hline 2.00 sine & 0.707 & 6.3102 & 0.8516 \\
2.25 sine & 0.795 & 7.659 & 0.9248 \\
2.50 sine & 0.884 & 8.1183 & 0.9665 \\
3.0 sine & 1.06 & 8.229 & 0.9336 \\
3.5 sine & 1.24 & 8.6806 & 0.9143 \\
\hline 2.0 square & 1.0 & 9.986 & 0.9458 \\
2.25 square & 1.13 & 11.041 & 0.9458 \\
2.5 square & 1.25 & 13.241 & 0.9852 \\
3.0 square & 1.50 & 11.013 & 0.9521 \\
3.5 square & 1.75 & 8.9271 & 0.9355 \\
\hline
\end{tabular}

\section{Solution Composition}

Nanostructures deposited using different concentrations of $\mathrm{Na}_{3} \mathrm{C}_{6} \mathrm{H}_{5} \mathrm{O}_{7}$ were all evaluated as potential SERS substrates. Figure $\mathrm{S} 12$ displays the impact the concentration of $\mathrm{Na}_{3} \mathrm{C}_{6} \mathrm{H}_{5} \mathrm{O}_{7}$ has on the nanostructures formed. The areas which displayed the greatest lateral growth had their measured and plotted in Figure S16. 


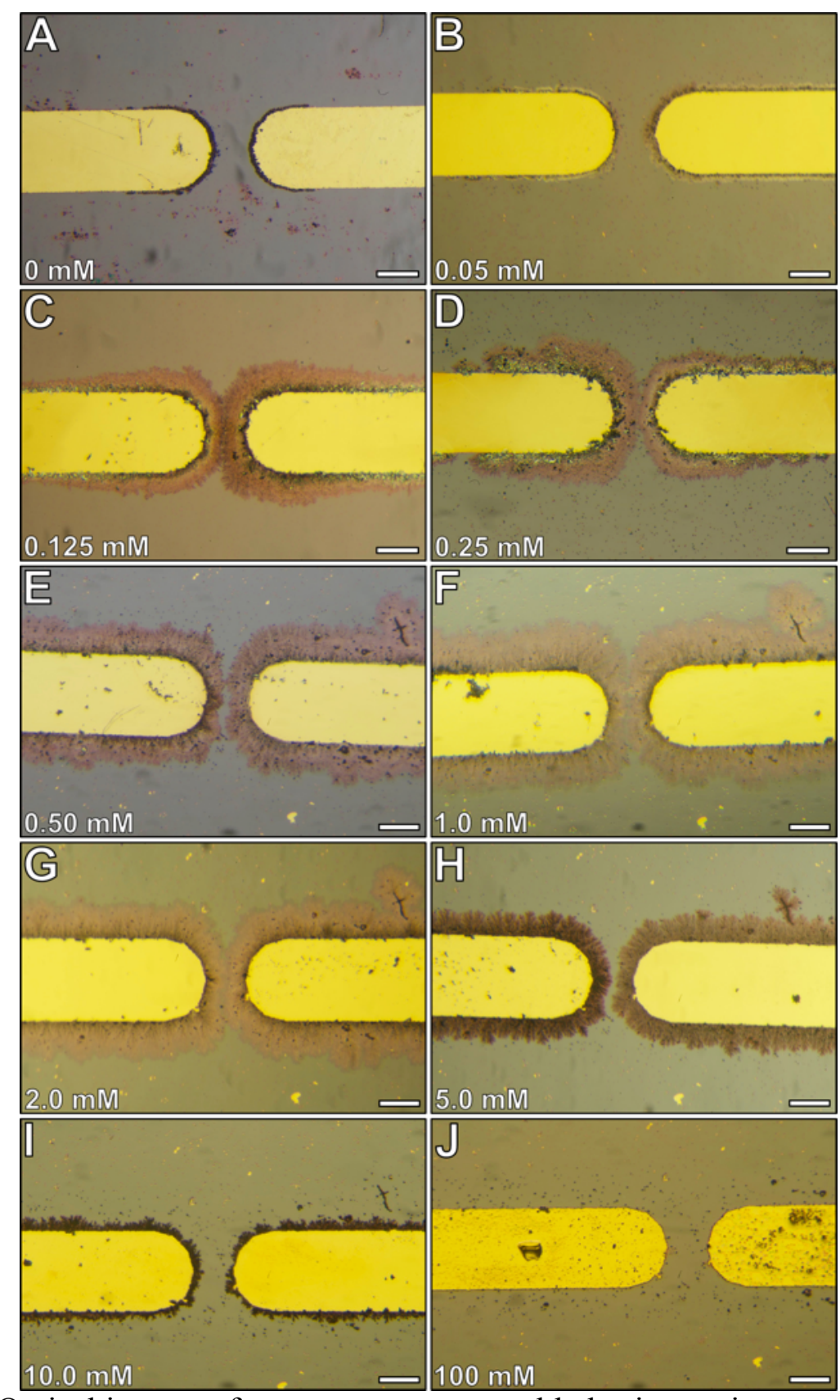

Figure S12: Optical images of nanostructures assembled using various concentrations of $\mathrm{Na}_{3} \mathrm{C}_{6} \mathrm{H}_{5} \mathrm{O}_{7}$ with $0.5 \mathrm{mM} \mathrm{AgNO} 3$ and a square electrical signal of $10 \mathrm{~Hz}$ and $3 \mathrm{Vpp}$ for 10 minutes. Scale bar is 100 microns.

Figure S13 displays the SERS signal of R6G on the various nanostructures shown in Figure S12. 

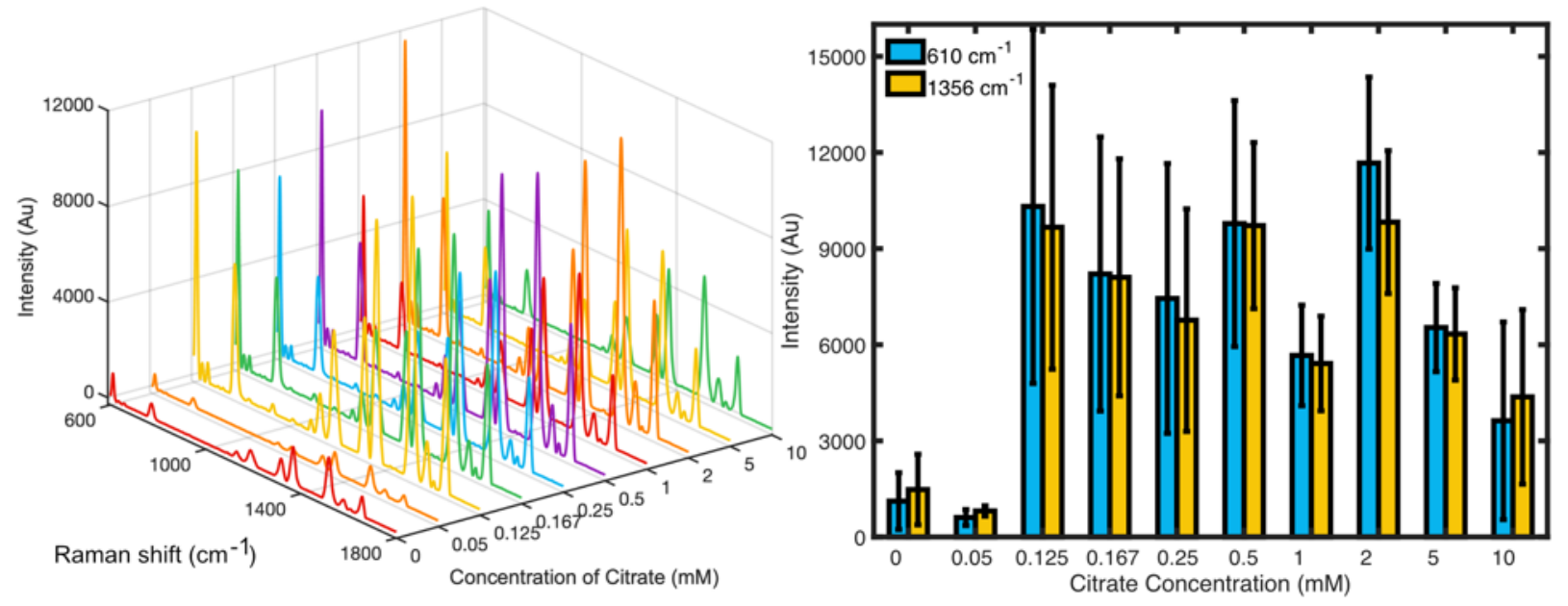

Figure S13: SERS signal of R6G $\left(10^{-5} \mathrm{M}\right)$ from nanostructures fabricated using different concentrations of $\mathrm{Na}_{3} \mathrm{C}_{6} \mathrm{H}_{5} \mathrm{O}_{7}$. Solutions all contained $0.5 \mathrm{mM} \mathrm{AgNO}_{3}$ and a square electrical signal of $3 \mathrm{Vpp}$ and $10 \mathrm{~Hz}$ for 10 minutes were used for all depositions.

The importance of a supporting electrolyte was tested using a low concentration of $\mathrm{Na}_{3} \mathrm{C}_{6} \mathrm{H}_{5} \mathrm{O}_{7}$ and adding $\mathrm{Na}_{2} \mathrm{SO}_{4}$. As seen in Figure S14, the addition of $\mathrm{Na}_{2} \mathrm{SO}_{4}$ greatly alters the morphology of the nanostructures formed. Adding $3 \mathrm{mM}$ of $\mathrm{Na}_{2} \mathrm{SO}_{4}$, the nanostructures are no longer tip focused and coat all edges of the microelectrodes. At $30 \mathrm{mM} \mathrm{NA}_{2} \mathrm{SO}_{4}$, the nanostructures failed to grow laterally and in fact failed to stay anchored to the surface when the droplet was removed. The excess $\mathrm{NA}_{2} \mathrm{SO}_{4}$, likely reduced the effect of migration due to electrical shielding and a smaller fraction of the current being carried by Ag ions. Ag ions which reach the electrodes are not solely directed by migration to attach to defects or extrusions on the growing nanostructures where the electric field is strongest. Instead the Ag ions are reduced and attached to the nanostructure in an almost non-preferential manner. Thus more spherical or aggregate like particles form on the edges of the microelectrodes rather than fractal nanostructures 

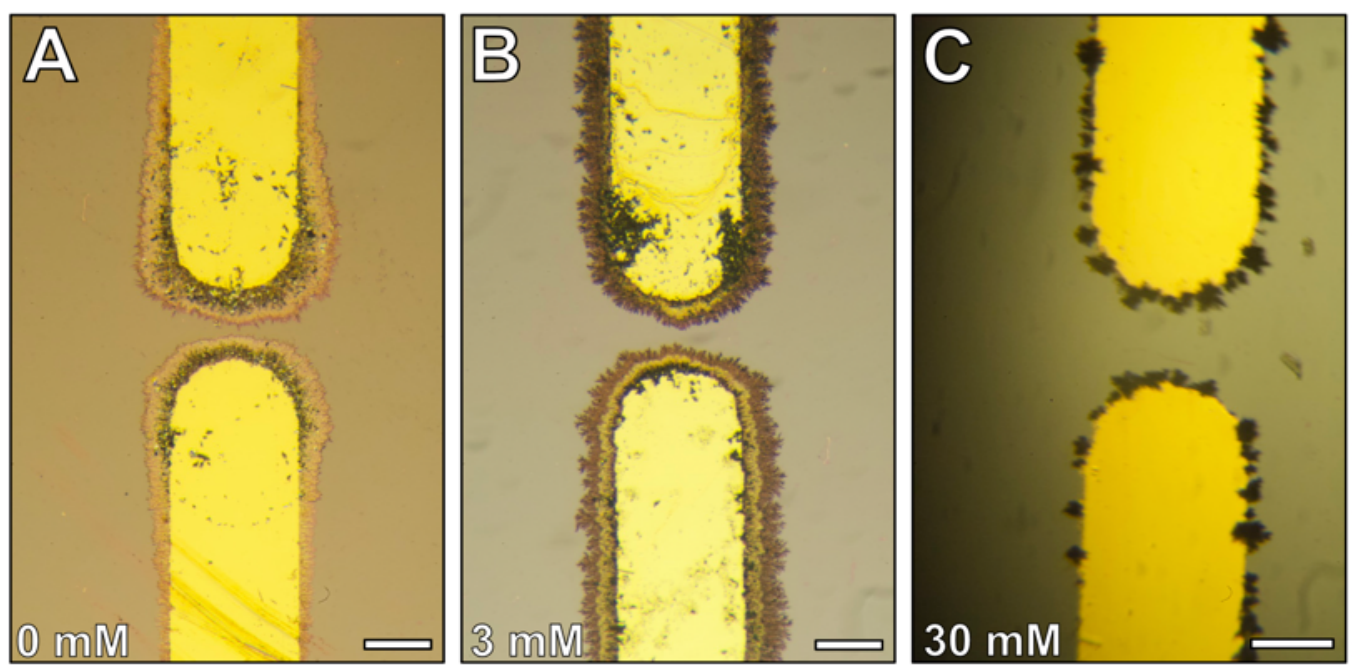

Figure S14: Deposition formed using various concentrations of $\mathrm{Na}_{2} \mathrm{SO}_{4}$. All structures were formed using a $0.125 \mathrm{mM} \mathrm{Na}_{3} \mathrm{C}_{6} \mathrm{H}_{5} \mathrm{O}_{7}$ and $0.5 \mathrm{mM} \mathrm{AgNO}_{3}$ solution and an electrical signal frequency of $10 \mathrm{~Hz}$ and $2.5 \mathrm{Vpp}$ for 10 minutes.

Testing with citric acid $\left(\mathrm{C}_{6} \mathrm{H}_{8} \mathrm{O}_{7}\right)$ was found to support our hypothesis on the roles $\mathrm{Na}_{3} \mathrm{C}_{6} \mathrm{H}_{5} \mathrm{O}_{7}$ plays. Using a solution of $2 \mathrm{mM} \mathrm{C}_{6} \mathrm{H}_{8} \mathrm{O}_{7}$ with $0.5 \mathrm{mM} \mathrm{AgNO}_{3}$, the structures formed coated the edges of the microelectrodes but failed to extend further than 5-10 microns from the edge (see Figure S15A). Only by adding sodium hydroxide $(\mathrm{NaOH})$, increasing $\mathrm{pH}$ from acidic conditions to neutral, did the growth of nanostructures improve and begin to resemble structures made with $\mathrm{Na}_{3} \mathrm{C}_{6} \mathrm{H}_{5} \mathrm{O}_{7}$ instead of $\mathrm{C}_{6} \mathrm{H}_{8} \mathrm{O}_{7}$. (Figure S15B-E). Raising the $\mathrm{pH}$ reduced the concentration of protons in solution thereby increasing the migration of $\mathrm{Ag}$ ions and also changed the protonation state of citric acid as described by the following equations: ${ }^{4}$

$$
\begin{aligned}
& C_{6} H_{8} O_{7} \leftrightarrow C_{6} H_{7} O_{7}^{-}+H^{+}, p K_{a 1}=3.2 \\
& C_{6} H_{7} O_{7}^{-1} \leftrightarrow C_{6} H_{6} O_{7}^{-2}+H^{+}, p K_{a 2}=4.8 \\
& C_{6} H_{6} O_{7}^{-2} \leftrightarrow C_{6} H_{5} O_{7}^{-3}+H^{+}, p K_{a 3}=6.4
\end{aligned}
$$

The deprotonated charged citrate anion has increasing probability of forming a complex with a $\mathrm{Ag}$ cation. Raising the $\mathrm{pH}$ to basic conditions, resulted in a structure which resembled a structure formed at low concentrations of $\mathrm{AgNO}_{3}$ (Figure $\mathrm{S} 15 \mathrm{~F}$ ). The higher $\mathrm{pH}$ would have pushed the deprotonation of $\mathrm{C}_{6} \mathrm{H}_{8} \mathrm{O}_{7}$ to -3 and a stronger Ag-citrate complex would have formed with the free $\mathrm{Ag}$ ion concentration being severely reduced. The solution was clear but some of the $\mathrm{Ag}$ ions may have also precipitated out of solution as Ag hydroxide. As a control, deposition was attempted at acidic conditions with $\mathrm{Na}_{2} \mathrm{SO}_{4}$ added as well; no deposition was seen (see figure S15G). 

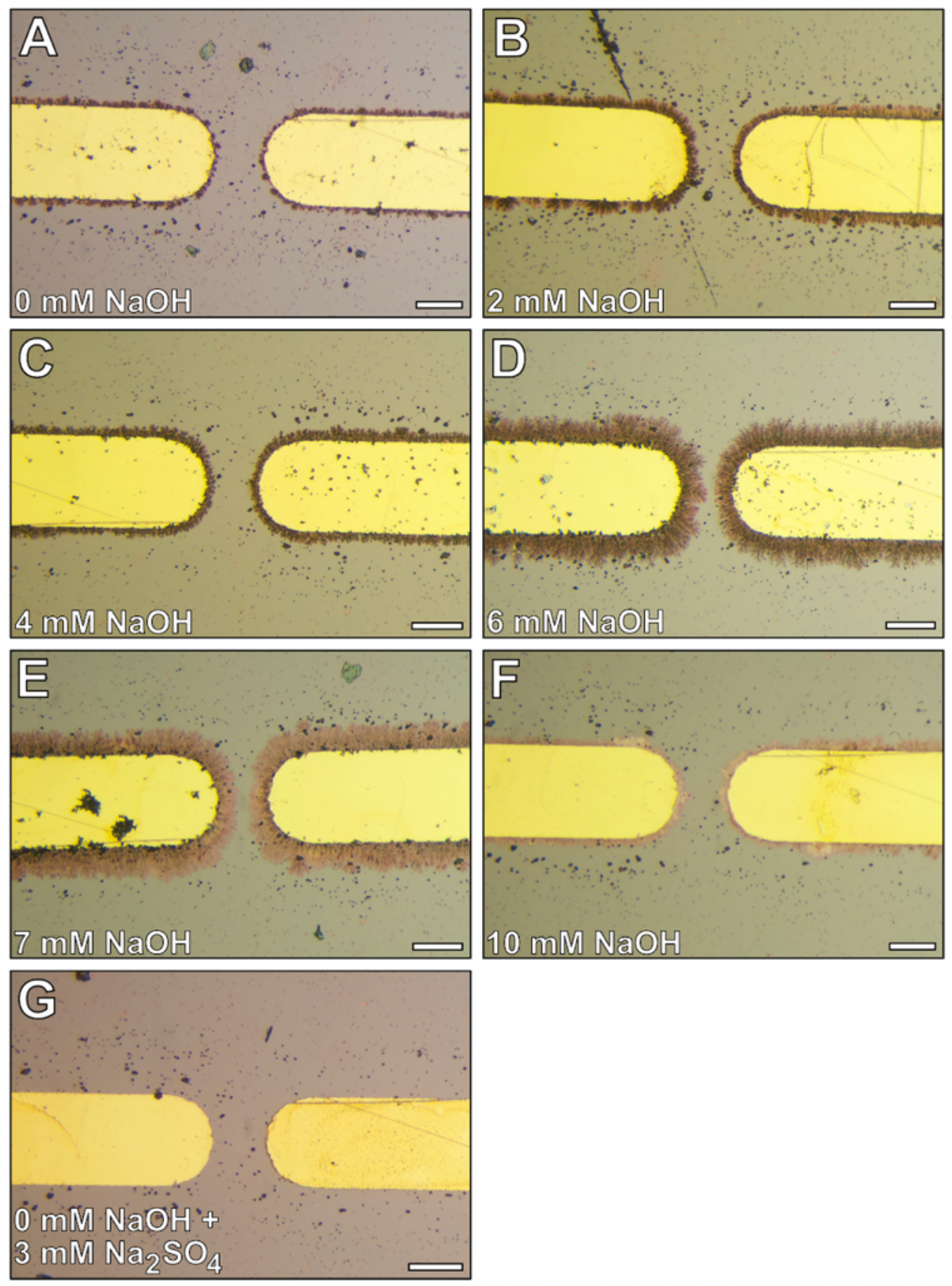

Figure S15: Depositions performed with varying concentrations of sodium hydroxide with $2 \mathrm{mM}$ citric acid, $0.5 \mathrm{mM} \mathrm{AgNO}_{3}$ and an electrical signal of $3.0 \mathrm{Vpp}$ and $10 \mathrm{~Hz} 10$ minutes. Scale bar is 100 microns. 

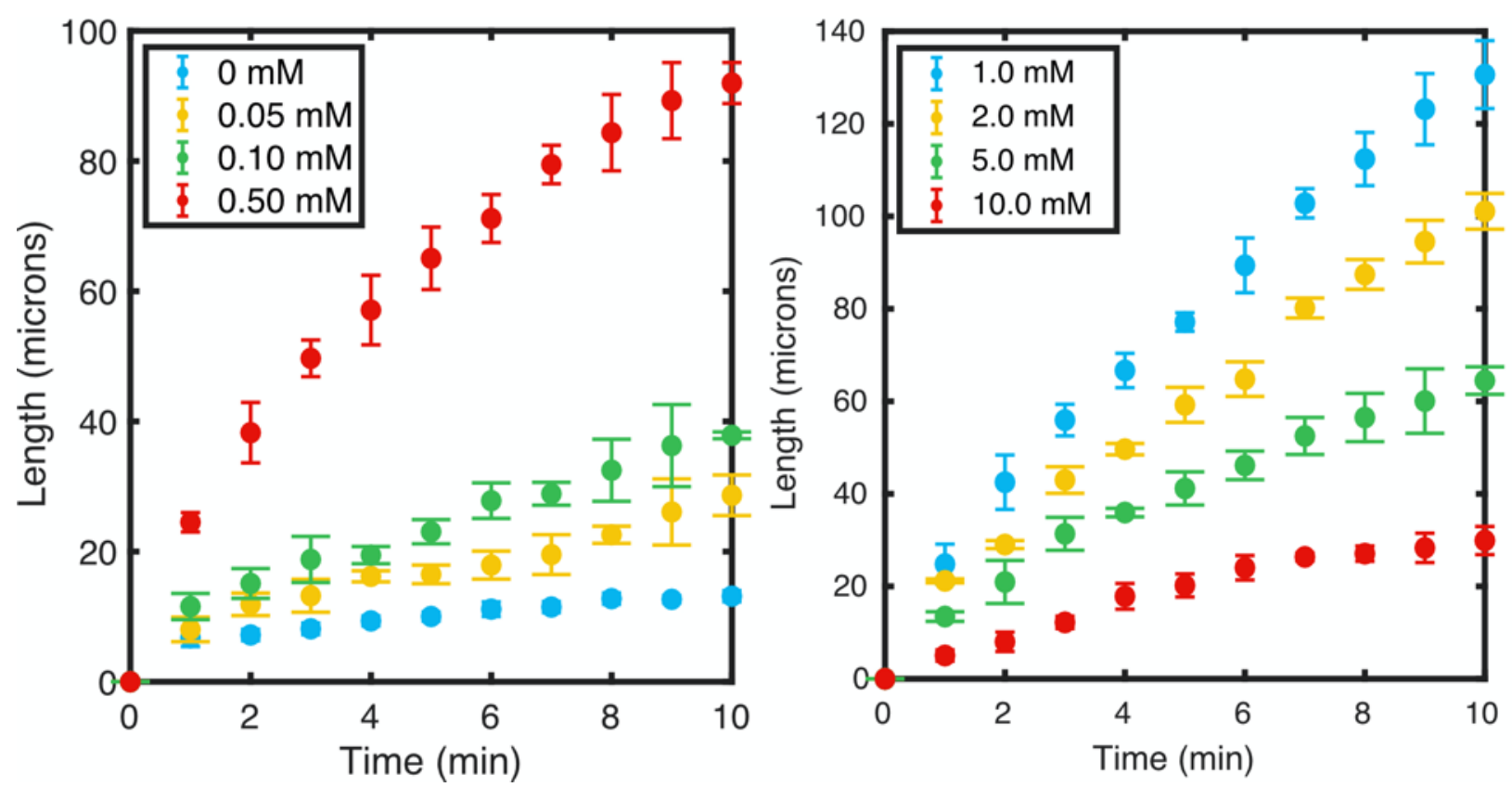

Figure S16: Max lateral growth of nanostructures assembled using various concentrations of $\mathrm{Na}_{3} \mathrm{C}_{6} \mathrm{H}_{5} \mathrm{O}_{7}$ with $0.5 \mathrm{mM} \mathrm{AgNO} 3$ and a square electrical signal of $10 \mathrm{~Hz}, 3 \mathrm{Vpp}$.

Figure $\mathrm{S} 17$ demonstrates how varying the concentration of $\mathrm{AgNO}_{3}$ can drastically alter the nanostructures formed. The growth of the nanostructures which displayed the largest lateral growth was measured and is plotted in Figure S18. It is important to note these are max values and not reflective of the average growth as the higher concentrations resulted in uneven growth on the electrode edges. 


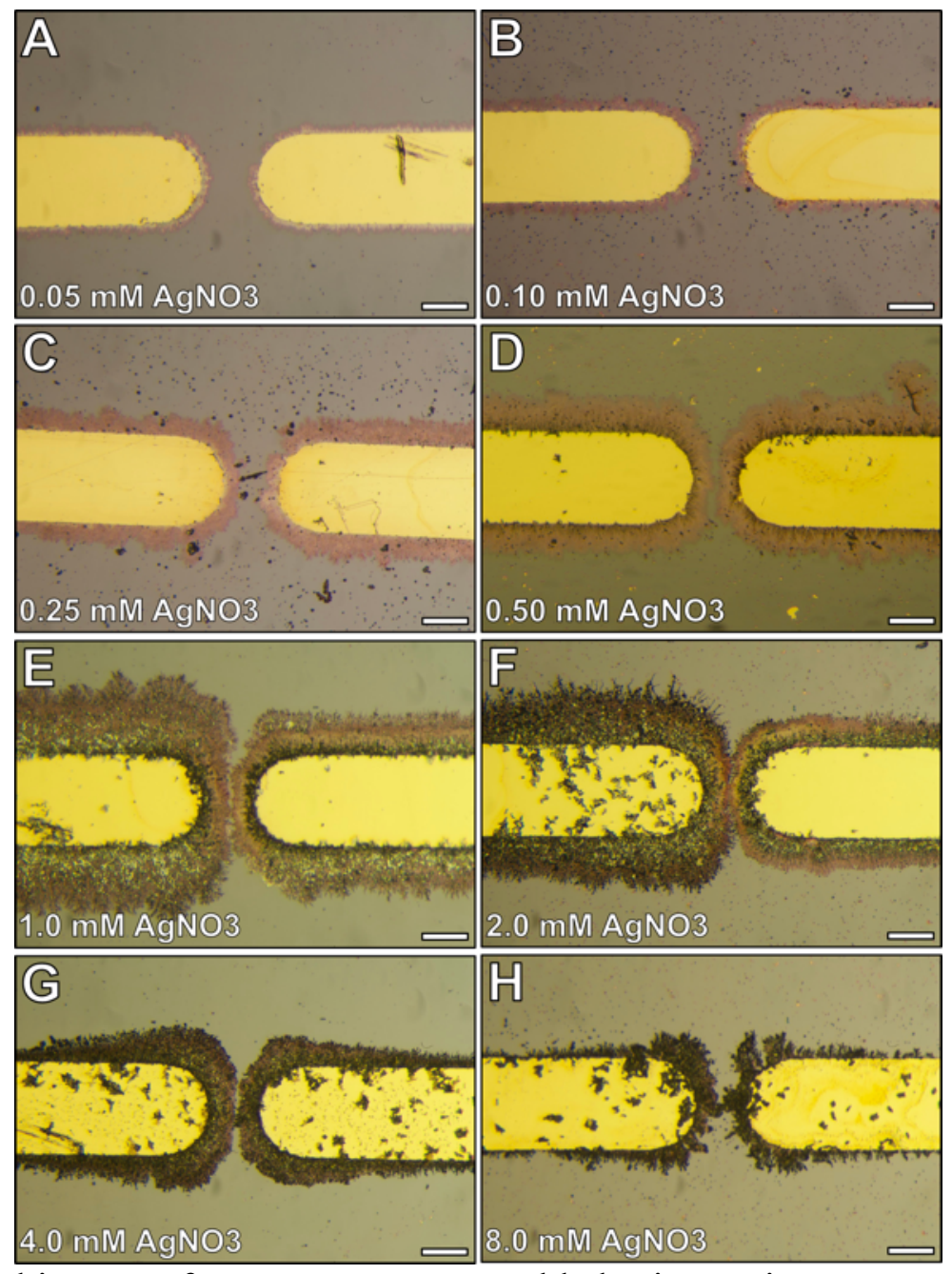

Figure S17: Optical images of nanostructures assembled using various concentrations of $\mathrm{AgNO}_{3}$ with $2.0 \mathrm{mM} \mathrm{Na}_{3} \mathrm{C}_{6} \mathrm{H}_{5} \mathrm{O}_{7} \mathrm{AgNO}_{3}$ and an electrical signal of $10 \mathrm{~Hz}$ and $3 \mathrm{Vpp}$ for 10 minutes. Scale bar is 100 microns. 

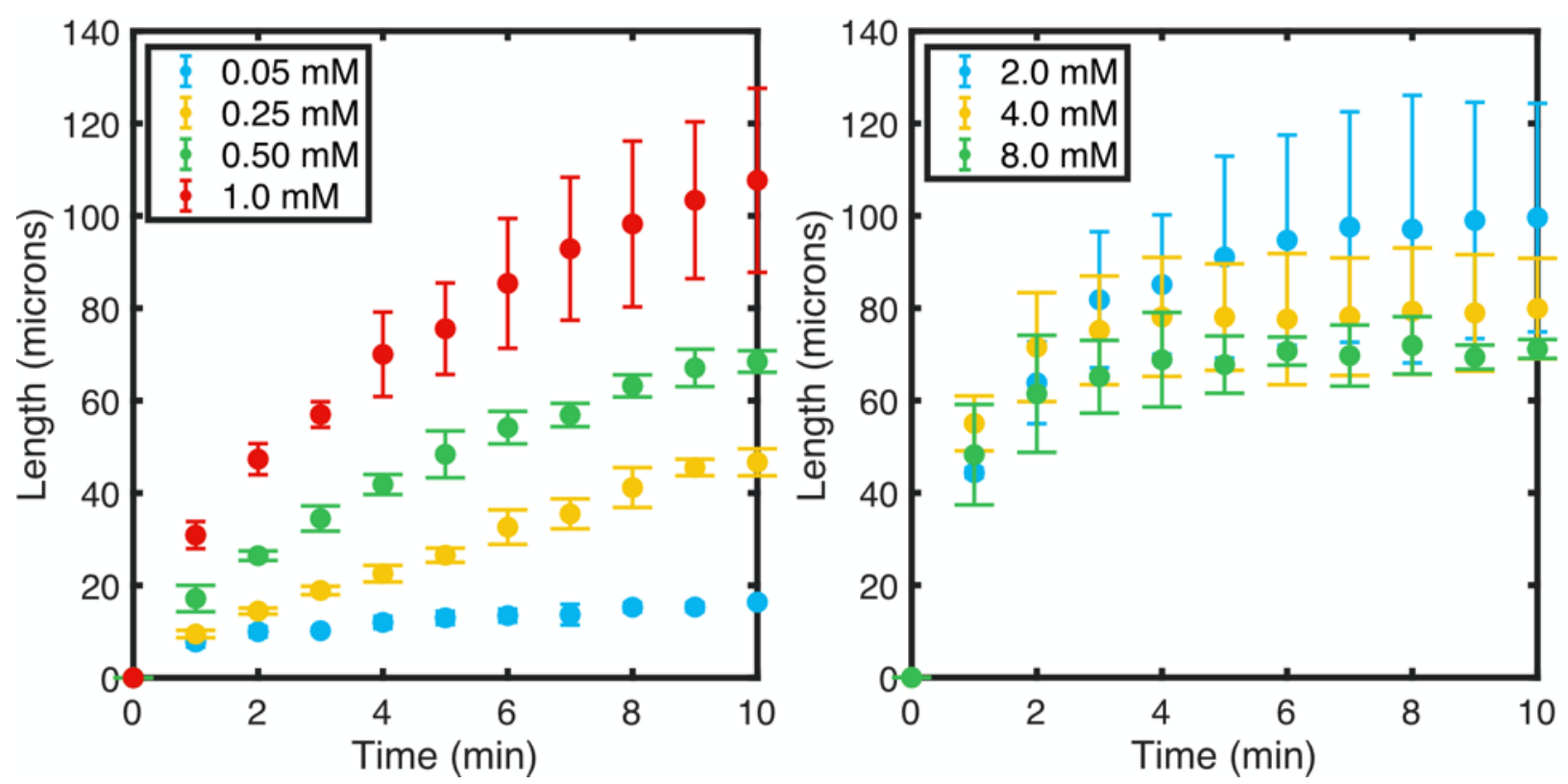

Figure S18: Max lateral growth of nanostructures assembled using various concentrations of $\mathrm{AgNO}_{3}$ with $2.0 \mathrm{mM} \mathrm{Na}_{3} \mathrm{C}_{6} \mathrm{H}_{5} \mathrm{O}_{7} \mathrm{AgNO}_{3}$ and an electrical signal of $10 \mathrm{~Hz}, 3 \mathrm{Vpp}$.

Nanostructures deposited using a 4:1 molar ratio of $\mathrm{Na}_{3} \mathrm{C}_{6} \mathrm{H}_{5} \mathrm{O}_{7}$ : $\mathrm{AgNO}_{3}$ had their largest lateral growth was measured and is plotted in Figure S19. The measurements were taken on the electrode edges away from the electrode gap.
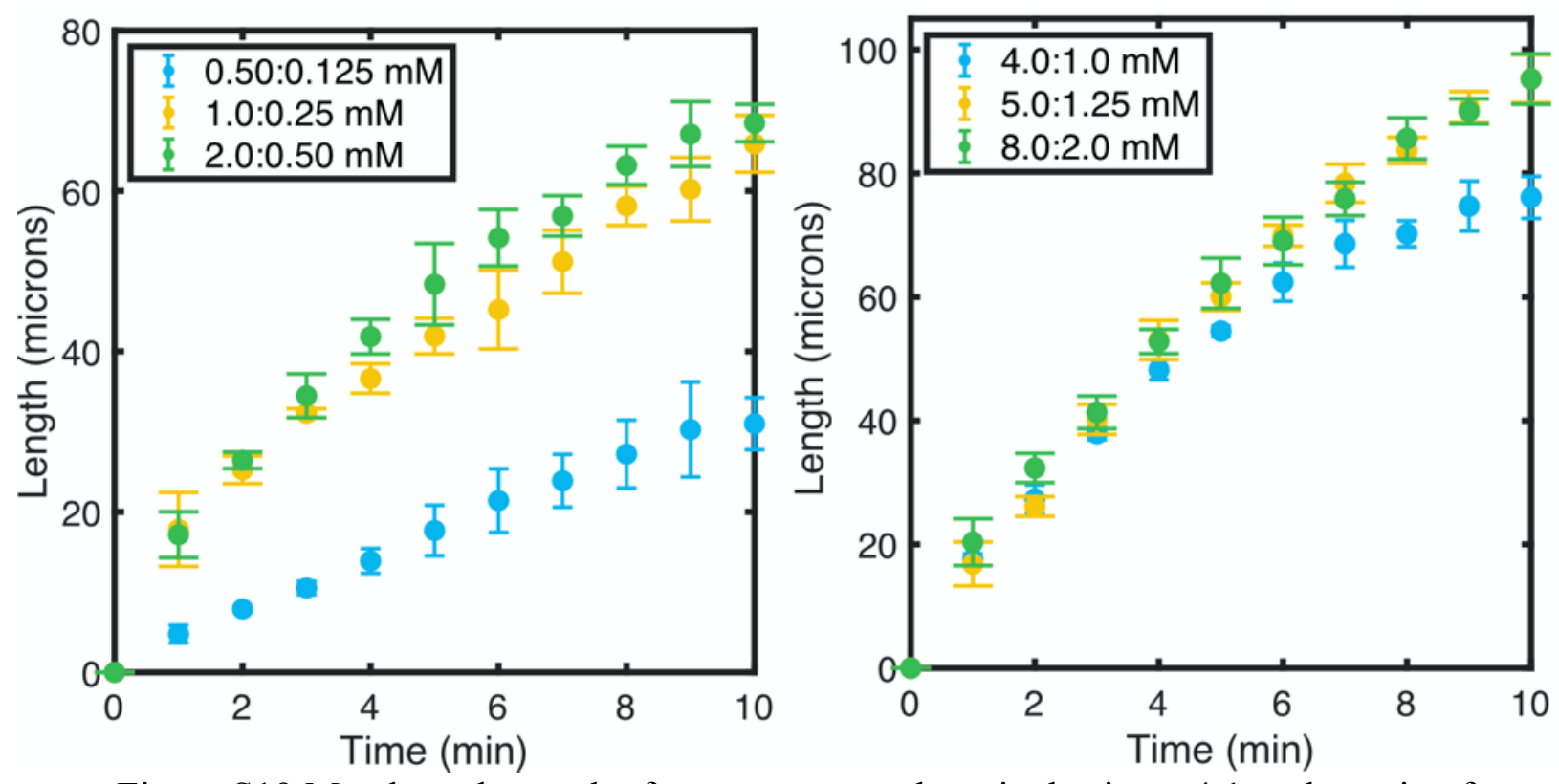

Figure S19:Max lateral growth of nanostructures deposited using a 4:1 molar ratio of $\mathrm{Na}_{3} \mathrm{C}_{6} \mathrm{H}_{5} \mathrm{O}_{7}: \mathrm{AgNO}_{3}$. An electrical signal of $3 \mathrm{Vpp}$ at $10 \mathrm{~Hz}$ was used during deposition. 
Nanostructures deposited using different concentrations of $\mathrm{Na}_{3} \mathrm{C}_{6} \mathrm{H}_{5} \mathrm{O}_{7}$ and $\mathrm{AgNO}_{3}$ with a 4:1 ratio between $\mathrm{Na}_{3} \mathrm{C}_{6} \mathrm{H}_{5} \mathrm{O}_{7}: \mathrm{AgNO}_{3}$ were all evaluated as potential SERS substrates. Figure $\mathrm{S} 20$ displays the SERS signal of R6G on the various nanostructures.
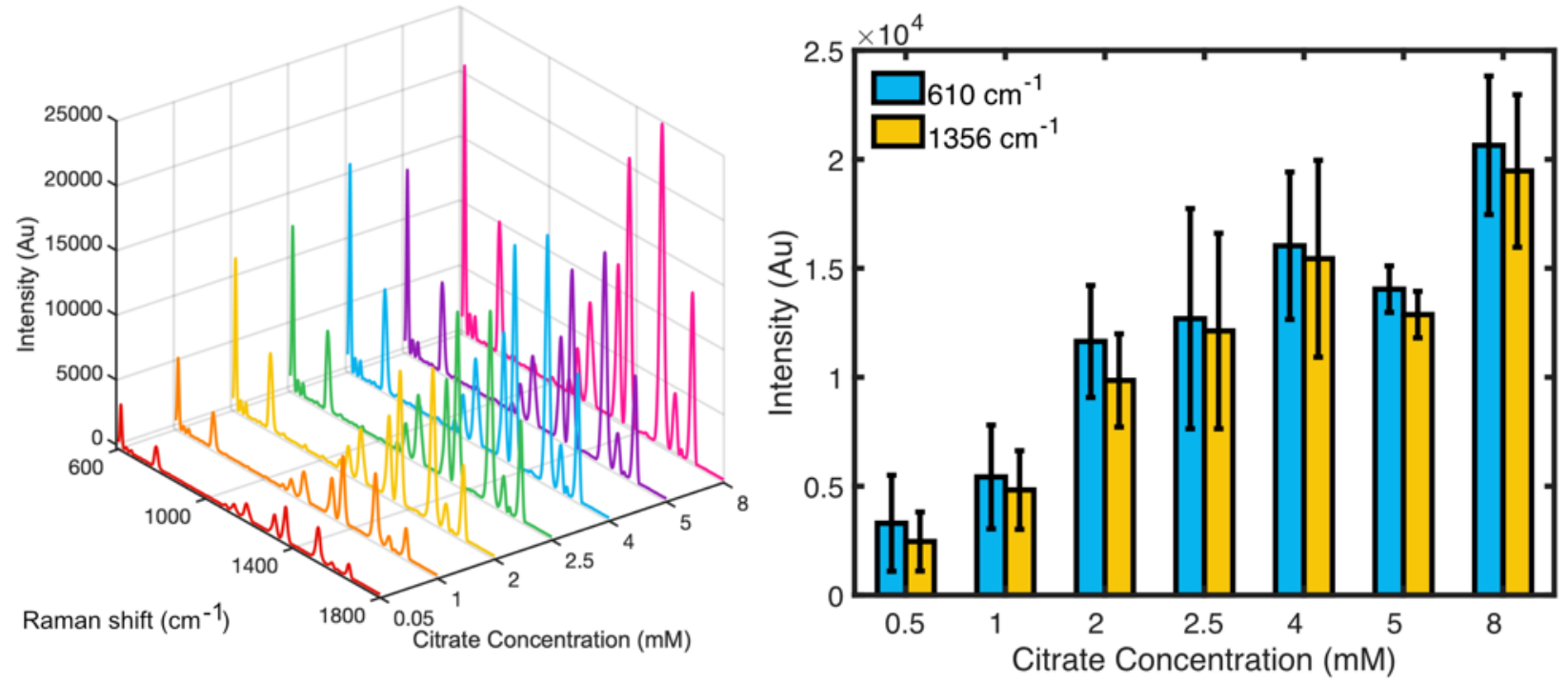

Figure S20: SERS signal of R6G $\left(10^{-5} \mathrm{M}\right)$ from nanostructures fabricated using diferent ion concentrations while maintaining a 4:1 molar ratio between $\mathrm{Na}_{3} \mathrm{C}_{6} \mathrm{H}_{5} \mathrm{O}_{7}: \mathrm{AgNO}_{3}$. An electrical signal of $10 \mathrm{~Hz}$ and $3 \mathrm{Vpp}$ for 10 minutes were used for all depositions.

\section{SERS}

As a means to further characterized the nanostructures, the limit of detection for nanostructures fabricated using a solution of $2.0 \mathrm{mM} \mathrm{Na}_{3} \mathrm{C}_{6} \mathrm{H}_{5} \mathrm{O}_{7}$ : and $0.5 \mathrm{mM}$ of $\mathrm{AgNO}_{3}$ and electrical signal of $10 \mathrm{~Hz}$ and $3 \mathrm{Vpp}$ was evaluated. The limit of blank and limit of detection were calculated using equations $\mathrm{S} 10$ and $\mathrm{S} 11^{5}$ :

$$
\begin{aligned}
& L o B=\mu_{\text {blank }}+1.645 * \sigma \_ \text {blank } \quad(\mathrm{S} 10) \\
& L o B=168.05+1.645 * 62.79 \\
& L o B=271.35 \\
& \begin{array}{c}
L o D=L o B+1.645 * \sigma_{10^{-10} M R 6 G}(\mathrm{~S} \\
L o D=271.35+1.645 * 76.14 \\
L o D=396.60
\end{array}
\end{aligned}
$$

Using a linear regression on the intensity values for the $610 \mathrm{~cm}-1$ peak at various concentrations (Figure S21A, equation S12), the limit of detection was calculated to be $2.3 \times 10^{-10} \mathrm{~mol} / \mathrm{L}$.

$$
\begin{array}{r}
\log _{10} \text { Intensity }=3.7061+0.115 * \log _{10}(R 6 G \text { Concentration }) \\
\log _{10} 396.60=3.7061+0.115 * \log _{10}(\text { LoD Concentration }) \\
\text { LoD Concentration }=2.3 * 10^{-10} \frac{\text { mol }}{\mathrm{L}}
\end{array}
$$


The potential application of the nanostructures was evaluated through the detection of the chemical hazards melamine and thiram. In an aqueous solution, melamine was detected at $1 \mathrm{ppm}$ and $100 \mathrm{ppb}$ as shown in Figure S21B with melamine's characteristic peak due to the ring breathing II mode clearly being present. ${ }^{6}$ Similarly, thiram was detected in apple juice at $1 \mathrm{ppm}$ with no sample preparation being required before analysis with thiram's characteristic peak being seen separate from the control sample. (Figure S21C). ${ }^{7}$
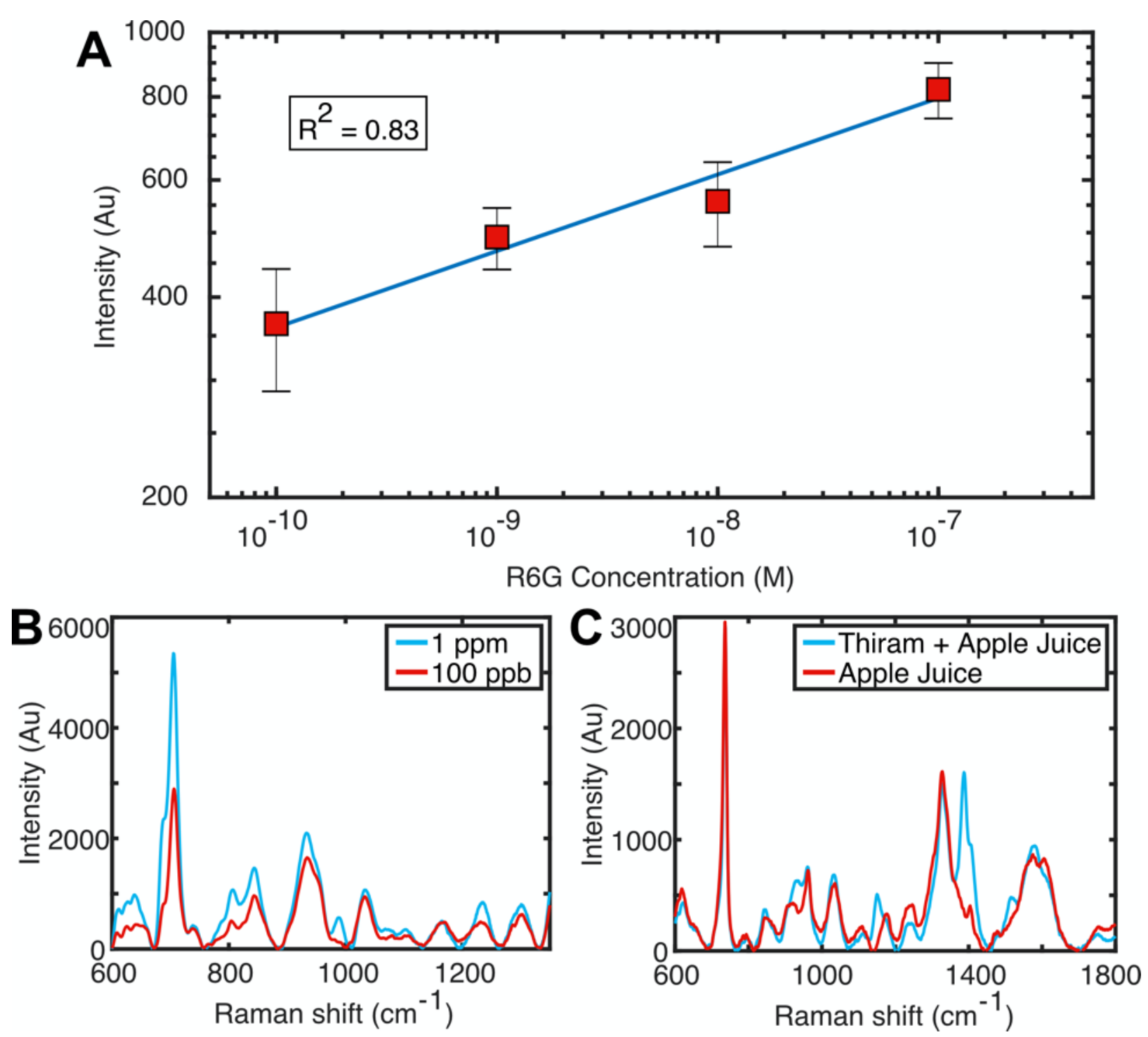

Figure S21: Various SERS spectra using nanostructures fabricated using a $2 \mathrm{mM} \mathrm{Na}_{3} \mathrm{C}_{6} \mathrm{H}_{5} \mathrm{O}_{7}$ and $0.5 \mathrm{mM} \mathrm{AgNO}_{3}$ solution and a frequency of $10 \mathrm{~Hz}$ with $3 \mathrm{Vpp}$ for 10 minutes. (A) Intensity of R6G's 610 peak at low concentrations. (B) Melamine in water at $1 \mathrm{ppm}$ and $100 \mathrm{ppb}$. (C) Apple juice and apple juice contaminated with thiram (1 ppm).

\section{References}

(1) Xu, Z.; Liu, Q.; Ling, J. An Evaluation of the van Oss-Chaudhury-Good Equation and 
Neumann's Equation of State Approach with Mercury Substrate. Langmuir 1995, 11 (3), 1044-1046. https://doi.org/10.1021/la00003a058.

(2) van Oss, C. J. Interfacial Forces in Aqueous Media, 2nd ed.; CRC Press: Boca Raton, 2006.

(3) Lindner, E.; Arias, E. Surface Free Energy Characteristics of Polyfluorinated Silane Films. Langmuir 1992, 8 (4), 1195-1198. https://doi.org/10.1021/la00040a029.

(4) Yang, Z.; Qian, H.; Chen, H.; Anker, J. N. One-Pot Hydrothermal Synthesis of Silver Nanowires via Citrate Reduction. J. Colloid Interface Sci. 2010, 352 (2), 285-291. https://doi.org/10.1016/j.jcis.2010.08.072.

(5) Armbruster, D. A.; Pry, T. Limit of Blank, Limit of Detection and Limit of Quantitation. Clin. Biochem. Rev. 2008, 29 Suppl 1 (August), S49-52.

(6) Zhang, X.-F.; Zou, M.-Q.; Qi, X.-H.; Liu, F.; Zhu, X.-H.; Zhao, B.-H. Detection of Melamine in Liquid Milk Using Surface-Enhanced Raman Scattering Spectroscopy. $J$. Raman Spectrosc. 2010, 41 (12), 1655-1660. https://doi.org/10.1002/jrs.2629.

(7) Wang, Q.; Wu, D.; Chen, Z. Ag Dendritic Nanostructures for Rapid Detection of Thiram Based on Surface-Enhanced Raman Scattering. RSC Adv. 2015, 5 (86), 70553-70557. https://doi.org/10.1039/C5RA13080H. 